\title{
Removal of reactive blue 19 from aqueous solution by pomegranate residual-based activated carbon: optimization by response surface methodology
}

\author{
Elham Radaei ${ }^{1}$, Mohammad Reza Alavi Moghaddam ${ }^{1 *}$ and Mokhtar Arami ${ }^{2}$
}

\begin{abstract}
Background: In this research, response surface methodology (RSM) was applied to optimize Reactive Blue 19 removal by activated carbon from pomegranate residual. A $2^{4}$ full factorial central composite design (CCD) was applied to evaluate the effects of initial $\mathrm{pH}$, adsorbent dose, initial dye concentration, and contact time on the dye removal efficiency.

Methodology: The activated carbon prepared by $50 \mathrm{wt} . \%$ phosphoric acid activation under air condition at $500^{\circ} \mathrm{C}$. The range of $\mathrm{pH}$ and initial dye concentration were selected in a way that considered a wide range of those variables. Furthermore, the range of contact time and adsorbent dose were determined based on initial tests. Levels of selected variables and 31 experiments were determined. MiniTab (version 16.1) was used for the regression and graphical analyses of the data obtained.

Results: It was found that the decrease of initial dye concentration and the increase of initial pH, adsorbent dose, and contact time are beneficial for improving the dye removal efficiency. Analysis of variance (ANOVA) results presented high $\mathrm{R}^{2}$ value of $99.17 \%$ for Reactive Blue 19 dye removal, which indicates the accuracy of the polynomial model is acceptable.

Conclusions: Initial pH of 11 , adsorbent dose of $1.025 \mathrm{~g} / \mathrm{L}$, initial dye concentration of $100 \mathrm{mg} / \mathrm{L}$, and contact time of 6.8 minutes found to be the optimum conditions. Dye removal efficiency of $98.7 \%$ was observed experimentally at optimum point which confirmed close to model predicted (98.1\%) result.
\end{abstract}

Keywords: Reactive dye, Adsorption, Pomegranate residual, Response surface methodology

\section{Introduction}

Many industries, especially textile and food industries often use dyes and pigments to color their products. As a result, these industries often discharge large amounts of colored effluents due to unfixed dyes on fibres or food during coloring and washing steps [1]. Due to the disposal of these effluents into the receiving water body may cause severe damage to aquatic biota and humans due to mutagenic and carcinogenic effects [2-4], it is of great importance to provide waste-treatment facilities for minimizing these substances in the effluents before discharge.

\footnotetext{
* Correspondence: Alavim@yahoo.com

'Department of Civil and Environmental Engineering, Amirkabir University of Technology (AUT), Tehran, Iran

Full list of author information is available at the end of the article
}

There are several methods available for treatment of dye-containing wastewater, such as membrane [5], electrochemical [6], coagulation/flocculation [7], and biological [8]. The adsorption technique has been found not only to be effective, but also practical in application for the dye-containing wastewater treatment, due to its high efficiency, simplicity, ease of operation, and the availability of a wide range of adsorbents $[9,10]$. Activated carbons (ACs) are widely used as the most efficient adsorbents. The chemical activation is often used to produce ACs and it involves mixing the feedstock with a chemical activating agent such as $\mathrm{H}_{3} \mathrm{PO}_{4}, \mathrm{ZnCl}_{2}$, and $\mathrm{KOH}$ [11-13].

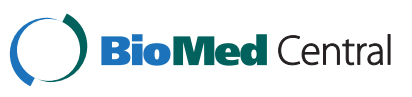

(c) 2014 Radaei et al.; licensee BioMed Central Ltd. This is an Open Access article distributed under the terms of the Creative Commons Attribution License (http://creativecommons.org/licenses/by/2.0), which permits unrestricted use, distribution, and reproduction in any medium, provided the original work is properly credited. 
Table 1 Chemical structure and characteristics of RB19

\begin{tabular}{ll}
\hline Characteristics & Values \\
\hline Molecular formula & $\mathrm{C}_{22} \mathrm{H}_{16} \mathrm{~N}_{2} \mathrm{Na}_{2} \mathrm{O}_{11} \mathrm{~S}_{3}$ \\
Molecular weight (MW) & 594 \\
Chemical structure & 626.54 \\
\hline
\end{tabular}

Conventional and classical methods of studying a process by maintaining other factors involved at an unspecified constant level does not depict the combined effect of all the factors involved. Response Surface Methodology (RSM) is a collection of mathematical and statistical techniques useful for developing, improving, and optimizing processes and can be used to evaluate the relative significance of several affecting factors even in the presence of complex interactions. The main objective of RSM is to determine the optimum operational conditions for the system or to determine a region that satisfies the operating specifications [14]. Many research groups applied this method for removal of different pollutants by adsorption process [14-19].

The aim of the present study is to optimize and model the removal of Reactive Blue 19 from aqueous solution by activated carbon derived from pomegranate residual using RSM. The relationship between dye removal efficiency and four main independent parameters including initial $\mathrm{pH}$, initial dye concentration, adsorbent dose, and contact time were evaluated by applying central composite design (CCD).

\section{Methods}

Materials and activated carbon preparation

Dye solution was prepared by dissolving Reactive blue 19 (RB19) which was provided by the Alvan Sabet

Table 2 Textural properties obtained by N2 adsorption/ desorption studies

\begin{tabular}{lll}
\hline Parameters & & Values \\
\hline BET surface area $\left(\mathrm{m}^{2} / \mathrm{g}\right)$ & $\mathrm{BET}^{\mathrm{a}}$ & 825.46 \\
Pore volume $\left(\mathrm{cm}^{3} / \mathrm{g}\right)$ & $\mathrm{BJH}$ adsorption & 0.3455 \\
Pore diameter $(\AA)$ & BJH adsorption & 14.35 \\
\hline
\end{tabular}

${ }^{\mathrm{a}}$ Computed in the $\mathrm{P} / \mathrm{P}_{0}$ range $0.05-0.30$.

${ }^{\mathrm{b}} \mathrm{BJH}$ (Barrett Joyner Halenda) cumulative adsorption pore volume for pores in range of 0 and $5000 \AA$ diameter.
Company and is widely used in textile industries in Iran. The chemical structure and characteristics of the selected dye is presented in Table 1 . The solution $\mathrm{pH}$ measurement was carried out using a 340i/SET $\mathrm{pH}$ meter (WTW-Germany) and was adjusted by $1 \mathrm{M}$ hydrochloric acid or $1 \mathrm{M}$ sodium hydroxide. The dye solution and adsorbent was agitated by a jar test at $150 \mathrm{rpm}$ agitation speed at ambient temperature $25^{\circ} \mathrm{C}$. A six beaker jar test apparatus from Zag-Chemi Company in Iran was used to simulate the adsorption process. All samples were filtered through glass fibre filters GF/A. The clear supernatants were analyzed for RB19 dye concentrations using a UV-vis HACH spectrophotometer (DR/4000).

In this study, pomegranate residual was collected from Meykhosh juice industry in Yazd/Iran. Pomegranate residual has been dried in an oven for $2 \mathrm{~h}$ at $100^{\circ} \mathrm{C}$ until a constant weight was reached. It was then ground in a ball mill and passed through sieve No.8. They were soaked for $24 \mathrm{~h}$ in the ratio of $1: 1(\mathrm{w} / \mathrm{v})$ with $50 \mathrm{wt} . \%$ phosphoric acid at room temperature. The sample is then decanted, dried in a muffle furnace for $1 \mathrm{~h}$ at $500^{\circ} \mathrm{C}$. Then the samples were washed sequentially several times with hot distilled water, until $\mathrm{pH}$ of the washing solution became neutral. In the last step, activated carbon $(\mathrm{AC})$ was powder and sieved by the No. 200 mesh.

The textural properties of adsorbent were also tested by $\mathrm{N}_{2}$ adsorption/desorption isotherms at $77 \mathrm{~K}$ using an Autosorb 1 analyzer (Quantachrome Corporation, USA). The specific surface area $\left(\mathrm{S}_{\mathrm{BET}}\right)$ was calculated by Brun- auer-Emmett-Teller (BET) method. The textural characteristics of AC are shown in Table 2. The pore size distribution was determined by using the Barrett-Joyner- Halenda (BJH) method (Figure 1).

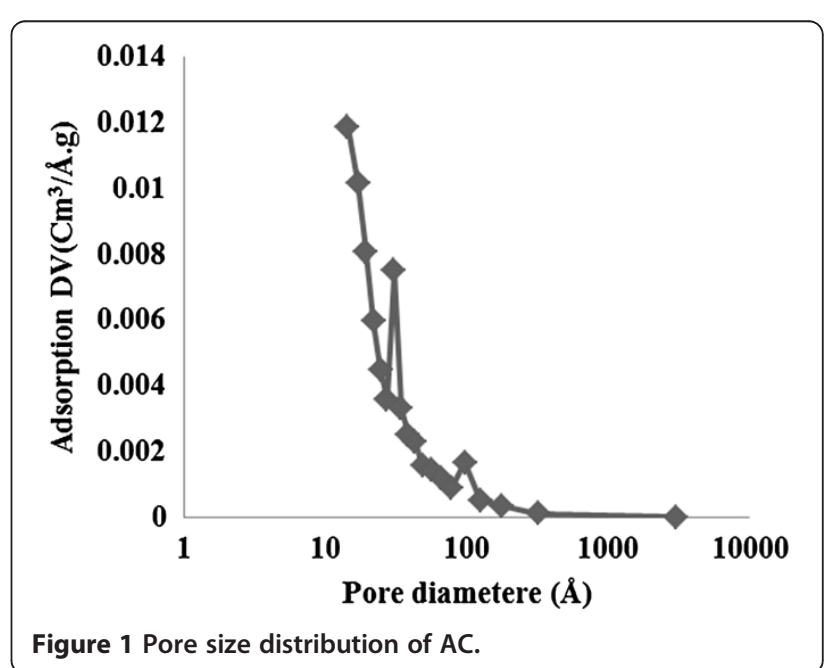




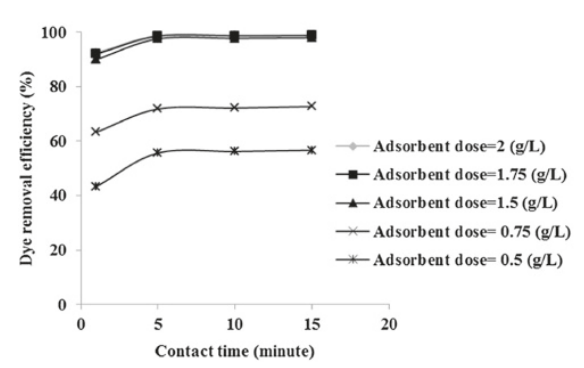

(a)

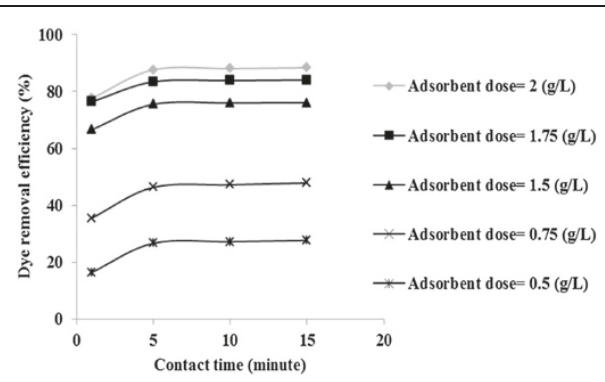

(b)

Figure 2 Results of initial tests for determining of adsorbent dose and contact time, initial $\mathrm{pH}=11$ : (a) initial dye concentration = $300 \mathrm{mg} / \mathrm{L}$ and (b) initial dye concentration $=500 \mathrm{mg} / \mathrm{L}$.

\section{Experimental design}

A central composite design (CCD) was employed for determining the optimum condition for the dye removal. A total of 31 experiments were carried out according to a $2^{4}$ full factorial CCD, consisting of 16 factorial experiments (coded to the usual \pm 1 notation), 8 axial experiments (on the axis at a distance of $\pm \alpha$ from the center), and 7 replicates (at the center of the experimental domain).

The value of $\alpha$ for rotatability depends on the number of points in the factorial portion of the design, which is given in equation (1):

$$
\alpha=\left(\mathrm{N}_{\mathrm{F}}\right)^{1 / 4}
$$

where $\mathrm{N}_{\mathrm{F}}$ is the number of points in the cube portion of the design $\left(\mathrm{N}_{\mathrm{F}}=2^{\mathrm{k}}, \mathrm{k}\right.$ is the number of factors). Therefore, $\alpha$ is equal to $\left(2^{4}\right)^{1 / 4}=2$ according to equation (1).

The range of $\mathrm{pH}$ and initial dye concentration were selected in a way that considered a wide range of those variables. The dye concentration was selected between 100 to $500 \mathrm{mg} / \mathrm{L}$. This range is based on determined actual concentration of textile wastewaters in Iran. The range of contact time and adsorbent dose were determined based on initial tests. The results of initial tests are shown in Figure 2. As demonstrated in the figures,

Table 3 Experimental range and levels of the independent variables

\begin{tabular}{lcccccc}
\hline Parameters & \multicolumn{5}{c}{ Levels } \\
\cline { 2 - 7 } & & $\mathbf{- a}$ & $\mathbf{- 1}$ & $\mathbf{0}$ & $\mathbf{1}$ & $\mathbf{a}$ \\
\hline Initial pH & $x_{1}$ & 3 & 5 & 7 & 9 & 11 \\
Adsorbent dose $(\mathrm{g} / \mathrm{L})$ & $\mathrm{x}_{2}$ & 0.75 & 1.00 & 1.25 & 1.50 & 1.75 \\
Initial dye concentration $(\mathrm{mg} / \mathrm{L})$ & $\mathrm{x}_{3}$ & 100 & 200 & 300 & 400 & 500 \\
Contact time $(\min )$ & $\mathrm{x}_{4}$ & 1 & 3 & 5 & 7 & 9 \\
\hline
\end{tabular}

Table 4 RSM design and its observed and predicted values

\begin{tabular}{|c|c|c|c|c|c|c|}
\hline \multirow[t]{2}{*}{ Run } & \multirow{2}{*}{$\begin{array}{l}\text { Initial } \\
\mathrm{pH} \\
\left(\mathrm{x}_{1}\right)\end{array}$} & \multirow{2}{*}{$\begin{array}{l}\text { Adsorbent } \\
\text { dose } \\
\left(x_{2}\right)\end{array}$} & \multirow{2}{*}{$\begin{array}{c}\text { Initial dye } \\
\text { concentration } \\
\left(\mathbf{x}_{3}\right)\end{array}$} & \multirow{2}{*}{$\begin{array}{c}\text { Contact } \\
\text { time } \\
\left(\mathrm{x}_{4}\right)\end{array}$} & \multicolumn{2}{|c|}{ Dye removal (\%) } \\
\hline & & & & & Experimental & Predicted \\
\hline 1 & 5 & 1 & 200 & 3 & 70.46 & 70.99 \\
\hline 2 & 9 & 1 & 200 & 3 & 71.57 & 72.39 \\
\hline 3 & 5 & 1.5 & 200 & 3 & 89.35 & 87.55 \\
\hline 4 & 9 & 1.5 & 200 & 3 & 91.64 & 92.28 \\
\hline 5 & 5 & 1 & 400 & 3 & 49.39 & 47.68 \\
\hline 6 & 9 & 1 & 400 & 3 & 51.40 & 52.31 \\
\hline 7 & 5 & 1.5 & 400 & 3 & 64.34 & 64.06 \\
\hline 8 & 9 & 1.5 & 400 & 3 & 72.00 & 72.01 \\
\hline 9 & 5 & 1 & 200 & 7 & 73.06 & 73.08 \\
\hline 10 & 9 & 1 & 200 & 7 & 74.41 & 74.71 \\
\hline 11 & 5 & 1.5 & 200 & 7 & 90.54 & 89.65 \\
\hline 12 & 9 & 1.5 & 200 & 7 & 92.84 & 94.59 \\
\hline 13 & 5 & 1 & 400 & 7 & 50.87 & 50.25 \\
\hline 14 & 9 & 1 & 400 & 7 & 53.28 & 55.11 \\
\hline 15 & 5 & 1.5 & 400 & 7 & 67.43 & 66.63 \\
\hline 16 & 9 & 1.5 & 400 & 7 & 75.32 & 74.80 \\
\hline 17 & 3 & 1.25 & 300 & 5 & 75.98 & 78.77 \\
\hline 18 & 11 & 1.25 & 300 & 5 & 91.19 & 88.35 \\
\hline 19 & 7 & 0.75 & 300 & 5 & 45.68 & 44.66 \\
\hline 20 & 7 & 1.75 & 300 & 5 & 79.95 & 80.92 \\
\hline 21 & 7 & 1.25 & 100 & 5 & 93.52 & 92.87 \\
\hline 22 & 7 & 1.25 & 500 & 5 & 49.17 & 49.78 \\
\hline 23 & 7 & 1.25 & 300 & 1 & 63.94 & 64.40 \\
\hline 24 & 7 & 1.25 & 300 & 9 & 69.80 & 69.29 \\
\hline 25 & 7 & 1.25 & 300 & 5 & 69.27 & 69.33 \\
\hline 26 & 7 & 1.25 & 300 & 5 & 70.50 & 69.33 \\
\hline 27 & 7 & 1.25 & 300 & 5 & 69.27 & 69.33 \\
\hline 28 & 7 & 1.25 & 300 & 5 & 68.30 & 69.33 \\
\hline 29 & 7 & 1.25 & 300 & 5 & 71.27 & 69.33 \\
\hline 30 & 7 & 1.25 & 300 & 5 & 67.47 & 69.33 \\
\hline 31 & 7 & 1.25 & 300 & 5 & 69.27 & 69.33 \\
\hline
\end{tabular}


Table 5 Statistical regression coefficients for RB19 removal efficiency $(\%)$ in coded units

\begin{tabular}{lcccc}
\hline Term & Coefficient & SE Coefficient & $\mathbf{T}$ & $\mathbf{P}$ \\
\hline Constant & 69.3371 & 0.6393 & 108.465 & 0.000 \\
$x_{1}$ & 2.3943 & 0.3452 & 6.935 & 0.000 \\
$x_{2}$ & 9.0655 & 0.3452 & 26.259 & 0.000 \\
$x_{3}$ & -10.7734 & 0.3452 & -31.206 & 0.000 \\
$x_{4}$ & 1.2223 & 0.3452 & 3.541 & 0.003 \\
$x_{1}^{2}$ & 3.5562 & 0.3163 & 11.244 & 0.000 \\
$x_{2}^{2}$ & -1.6346 & 0.3163 & -5.168 & 0.000 \\
$x_{3}^{2}$ & 0.4977 & 0.3163 & 1.573 & 0.135 \\
$x_{4}^{2}$ & -0.6212 & 0.3163 & -1.964 & 0.067 \\
$x_{1} x_{2}$ & 0.8284 & 0.4228 & 1.959 & 0.068 \\
$x_{1} x_{3}$ & 0.8070 & 0.4228 & 1.909 & 0.074 \\
$x_{1} x_{4}$ & 0.0549 & 0.4228 & 0.130 & 0.898 \\
$x_{2} x_{3}$ & -0.0465 & 0.4228 & -0.110 & 0.914 \\
$x_{2} x_{4}$ & -0.0007 & 0.4228 & -0.002 & 0.999 \\
$x_{3} x_{4}$ & 0.1210 & 0.4228 & 0.286 & 0.778 \\
\hline
\end{tabular}

the dye was rapidly adsorbed at a high rate in the first 5 minute, and after 10 minutes leveled off. Therefore, the range of contact time was considered between $1 \mathrm{mi}$ nute and 10 minutes. Due to a slight difference between dye removal efficiencies for adsorbent dose of $2 \mathrm{~g} / \mathrm{L}$ and $1.75 \mathrm{~g} / \mathrm{L}$, the maximum amount of adsorbent dose was considered $1.75 \mathrm{~g} / \mathrm{L}$. In addition, adsorbent dose of lower than $0.75 \mathrm{~g} / \mathrm{L}$ was not enough efficient to remove RB19.

Levels of selected variables are presented in Table 3. For statistical calculations, the variables $\mathrm{X}_{\mathrm{i}}$ (the real value of an independent variable) were coded as $\mathrm{x}_{\mathrm{i}}$ (dimensionless value of an independent variable) according to equation (2):

$$
\mathrm{x}_{\mathrm{i}}=\left(\mathrm{X}_{\mathrm{i}}-\mathrm{X}_{0}\right) / \Delta \mathrm{X}
$$

where $\mathrm{X}_{0}$ is the value of $\mathrm{X}_{\mathrm{i}}$ at the center point and $\Delta \mathrm{X}$ represents the step change.

Table 6 ANOVA for RB19 removal efficiency (\%)

\begin{tabular}{lcccccc}
\hline Source & DF & Seq SS & Adj SS & Adj MS & F & P \\
\hline Regression & 14 & 5455.27 & 5455.27 & 389.66 & 136.22 & 0.000 \\
Linear & 4 & 4931.44 & 4931.44 & 1232.86 & 430.99 & 0.000 \\
Square & 4 & 502.12 & 502.12 & 125.53 & 43.88 & 0.000 \\
Interaction & 6 & 21.72 & 21.72 & 3.62 & 1.27 & 0.327 \\
Residual error & 16 & 45.77 & 45.77 & 2.86 & & \\
Lack-of-fit & 10 & 36.11 & 36.11 & 3.61 & 2.24 & 0.168 \\
Pure error & 6 & 9.66 & 9.66 & 1.61 & & \\
Total & 30 & 5501.04 & & & & \\
\hline
\end{tabular}

Note: $R^{2}=99.17 \%, R^{2}(a d j)=98.44 \%$.
The behavior of the adsorption process is explained by the following empirical second-order polynomial model equation (3):

$$
Y_{i}=b_{0}+\sum_{i=1}^{n} b_{i} x_{i}+\sum_{i=1}^{n} b_{i i} x_{i}^{2}+\sum_{i=1}^{n-1} \sum_{j=i+1}^{n} b_{i j} x_{i} x_{j}
$$

where $\mathrm{Y}$ is the predicted response (dye removal efficiency), $b_{0}$ the constant coefficient, $b_{i}$ the linear coefficients, $b_{i i}$ the quadratic coefficients, $b_{i j}$ the interaction coefficients and $x_{i}, x_{j}$ are the coded values of the variables. MiniTab (version 16.1) was used for the regression and graphical analyses of the data obtained. The reliability of the fitted model was justified through ANOVA and the coefficient of $R^{2}$.

\section{Results}

\section{Statistical analysis}

The experimental design matrix, the experimental results and the predicted dye removal efficiency are presented in Table 4. The final model is expressed by equation (4):

$$
\begin{aligned}
\mathrm{Y}= & 69.3371+2.3943 \mathrm{x}_{1}+9.0655 \mathrm{x}_{2}-10.7734 \mathrm{x}_{3} \\
& +1.2223 \mathrm{x}_{4}+3.5562 \mathrm{x}_{1}{ }^{2}-1.6346 \mathrm{x}_{2}{ }^{2} \\
& +0.4977 \mathrm{x}_{3}{ }^{2}-0.6212 \mathrm{x}_{4}{ }^{2}+0.8284 \mathrm{x}_{1} \mathrm{x}_{2} \\
& +0.8070 \mathrm{x}_{1} \mathrm{x}_{3} \\
& +0.0549 \mathrm{x}_{1} \mathrm{x}_{4}-0.0465 \mathrm{x}_{2} \mathrm{x}_{3}-0.0007 \mathrm{x}_{2} \mathrm{x}_{4} \\
& +0.1210 \mathrm{x}_{3} \mathrm{x}_{4}
\end{aligned}
$$

Statistical regression coefficients for RB19 dye removal efficiency (\%) is provided in Table 5. Amounts of $\mathrm{P}(\mathrm{P}<0.05)$ for all independent parameters confirms that four selected factors are significant. However, it was found that all square and interaction terms except $x_{1}^{2}$ and $x_{2}^{2}$ (P values of 0.000 ) were insignificant to the response. ANOVA for the selected dye removal is also listed in Table 6. In this case, the P-value of $0.000(\mathrm{P}<$ 0.05 ) for regression model equation implies that the second-order polynomial model fitted to the experimental results well. The lack-of-fit was also calculated from the experimental error (pure error) and residuals. "F-value of Lack-of-fit" of 2.24 implies the significance of model correlation between the variables and process response for dye removal. Additionally, the value of $R^{2}=99.17 \%$ and $R^{2}(\operatorname{adj})=98.44 \%$ confirm the accuracy of the model. Furthermore, parity plot for the experimental and predicted value of RB19 removal efficiency (\%) is demonstrated in Figure 3.

In addition, normal probability and residuals versus fitted values plots for RB19 removal efficiency are illustrated in Figure 4. Normal probability plot is a suitable graphical method for judging the normality of the residuals [18]. As seen in Figure 4(a), the 


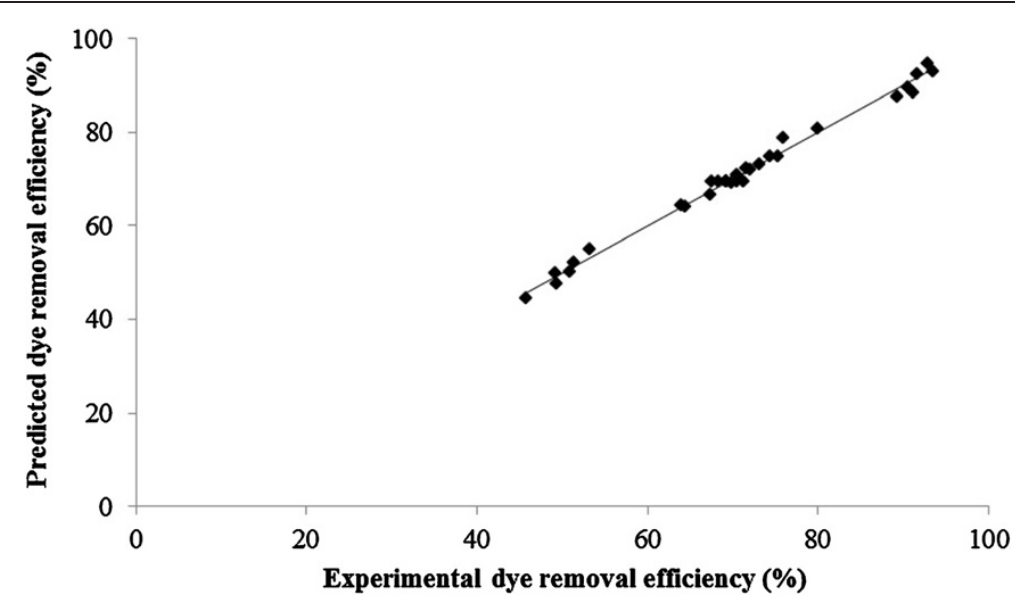

Figure 3 Parity plot for the experimental and predicted value of RB19 removal efficiency (\%).

normality assumption was relatively satisfied as the points in the plot form a fairly straight line. The reliability of the model was also examined with the plot of residuals versus fits in Figure 4(b). As Figure 4(b) shows, the number of increasing or decreasing points was significantly close; patterns of increasing residuals and increasing fits were similar; and, positive and negative residuals were scattered in same range. As a result, Figure 4 shows that the model is adequate to describe RB19 removal efficiency by response surface methodology for AC.

\section{Response surface and counter plotting for evaluation of operational parameters}

The main effect of each parameter on the dye removal efficiency is showed in Figure 5. As illustrated in
Figure $5(\mathrm{a}, \mathrm{b}, \mathrm{c})$, by increasing of initial $\mathrm{pH}$ and adsorbent dose, and decreasing of initial dye concentration, the dye removal efficiency improved. Moreover, as shown in Figure 5(d), adsorption efficiency rapidly increased with an increase in contact time within the first minutes. Then, the rate of adsorption was found to be relatively slow and then constant. As shown in this Figure, the dye removal is highly dependent on adsorbent dose and initial dye concentration, and the initial $\mathrm{pH}$ and contact time slightly influenced the process efficiency.

For a better explanation of the independent variables and their interactive effects on the dye removal, $3 \mathrm{D}$ plots and its corresponding contour plots are represented in Figure 6. At constant value of the initial dye concentration $(300 \mathrm{mg} / \mathrm{L})$, when the adsorbent

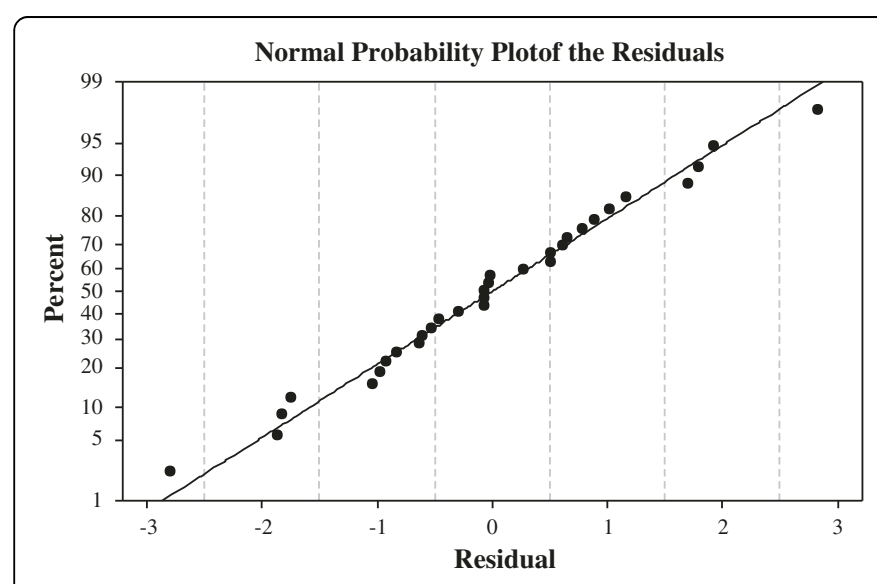

(a)

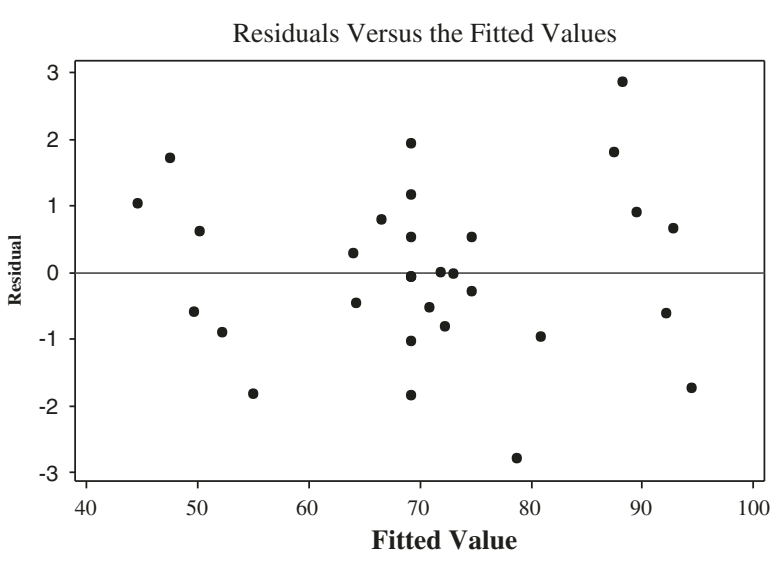

(b)

Figure 4 (a) Normal probability plot and (b) residual versus fit plot for RB19 removal efficiency (\%). 


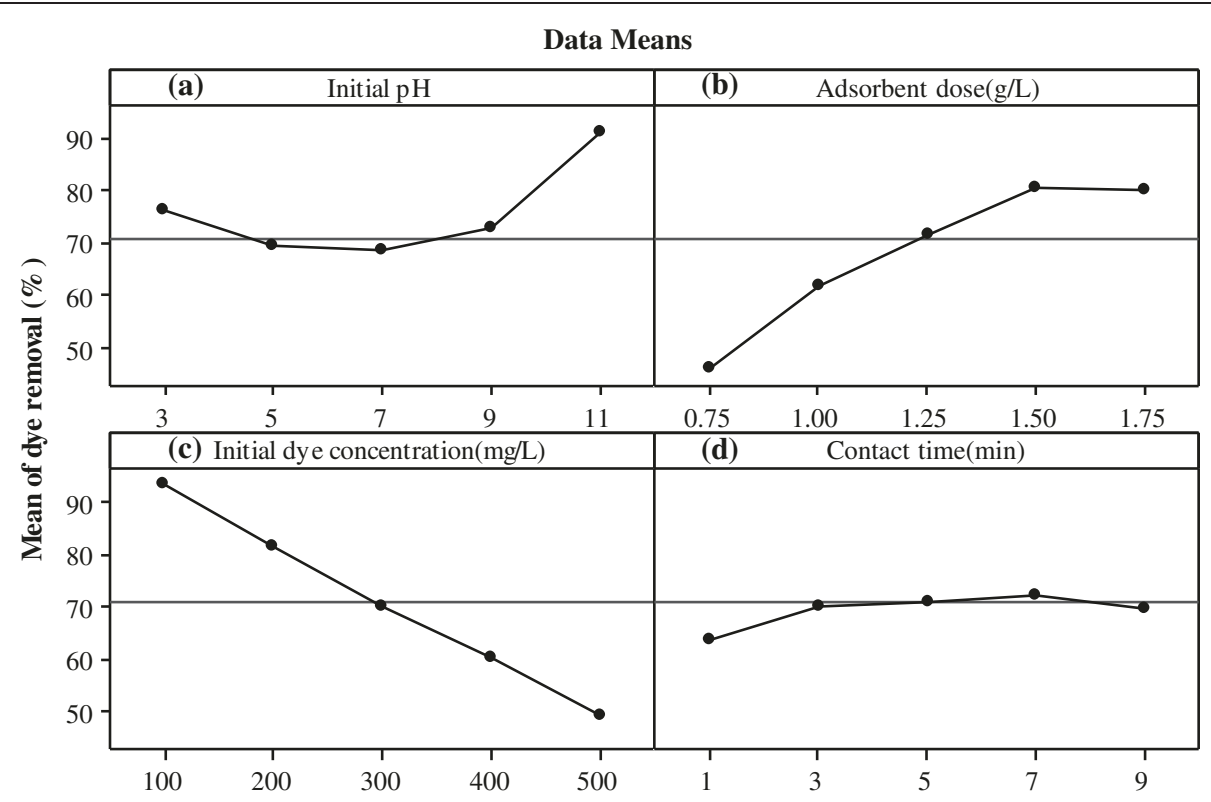

Figure 5 Main effect plots of parameters for RB19 removal efficiency: (a) initial pH, (b) adsorbent dose, (c) initial dye concentration and (d) contact time.

dose and initial $\mathrm{pH}$ increase, the dye removal efficiency increases and finally reaches to 100\% (Figure 6 (a)). Moreover, for given initial dye concentration of $100 \mathrm{mg} / \mathrm{L}$ and adsorbent dose of $1.25 \mathrm{~g} / \mathrm{L}$, dye removal efficiency is almost independent of initial $\mathrm{pH}$ (Figure 6(b)). This independency is due to the existence of numerous active sites for the adsorption, whereas the independency was decreased with increasing of initial dye concentration. As shown in Figure 6(c), there are no significant changes on the dye removal surface with the increase of contact time and initial $\mathrm{pH}$.

\section{Process optimization}

In order to determine the optimum conditions by the adsorption process, the desired aim in terms of RB19 removal efficiency was defined as target to achieve 98\% removal efficiency. The optimum values of the process parameters were calculated in coded units $\left(\mathrm{x}_{\mathrm{i}}\right)$ and then converted into uncoded units $\left(\mathrm{X}_{\mathrm{i}}\right)$ using Equation (1). Initial $\mathrm{pH}$ of 11, adsorbent dose of $1.025 \mathrm{~g} / \mathrm{L}$, initial dye concentration of $100 \mathrm{mg} / \mathrm{L}$ and contact time of 6.8 minutes found to be the optimum conditions by the model. The optimum condition was repeated three times and dye removal efficiencies of 98.4, 98.6, and 99.1\% were resulted. The average of 98.7\% dye removal efficiency was found close to the model prediction of $98.1 \%$.

\section{Discussion}

According to the results, contact time is the least important parameter, which is reported by other research groups $[20,21]$. Furthermore, by increasing of initial $\mathrm{pH}$ and adsorbent dose, and decreasing of initial dye concentration, the dye removal efficiency improved. These results are in good agreement with of previous studies $[22,23]$.

The effect of the four selected independent parameters and interactions among the RSM were analyzed which was shown that some interactions like $\left(\mathrm{x}_{1}^{2}\right.$ and $\mathrm{x}_{2}^{2}$ ) influenced the adsorption performance as well as all selected parameters. ANOVA showed a high $\mathrm{R}^{2}$ value of regressions model equation $\left(R^{2}=0.9917\right)$, thus ensuring a satisfactory adjustment of the second-order regression model with the experimental data. The optimum RB19 removal efficiency were found at initial $\mathrm{pH}$ of 11 , adsorbent dose of $1.025 \mathrm{~g} / \mathrm{L}$, initial dye concentration of $100 \mathrm{mg} / \mathrm{l}$ and contact time of $6.8 \mathrm{~min}$. An experiment was performed in optimum conditions which confirmed that the model and experimental results are in close agreement (98.7\% compared to $98.1 \%$ for the model).

\section{Conclusions}

In this research, response surface methodology was applied as an experimental design to explore the optimal conditions for RB19 dye removal from aqueous solutions by activated carbon prepared by pomegranate 


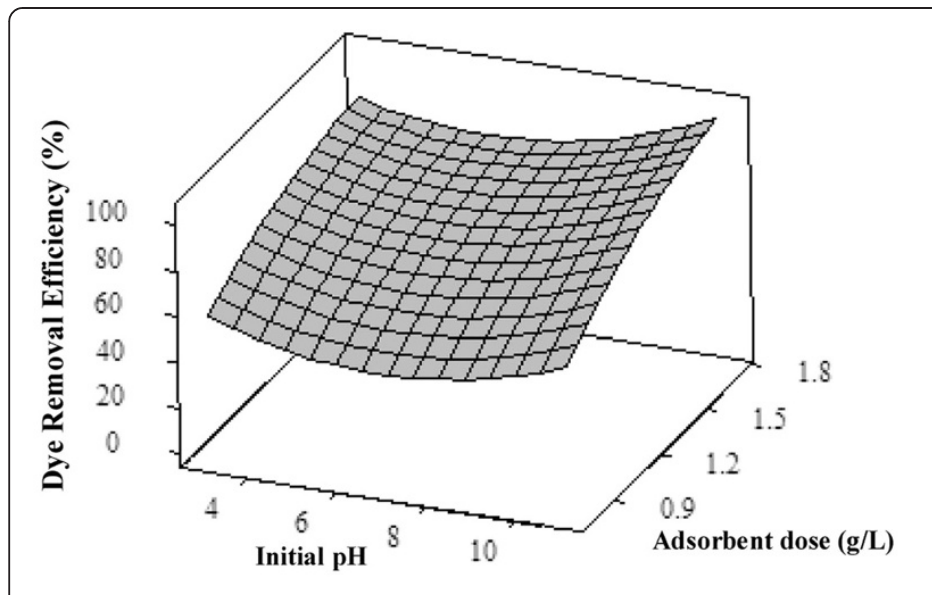

(a)

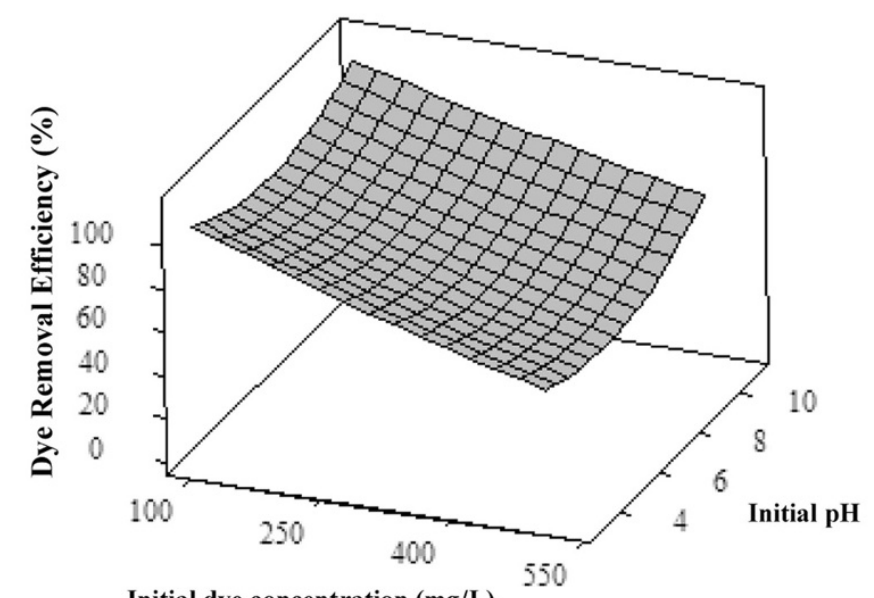

Initial dye concentration $(\mathrm{mg} / \mathrm{L})$

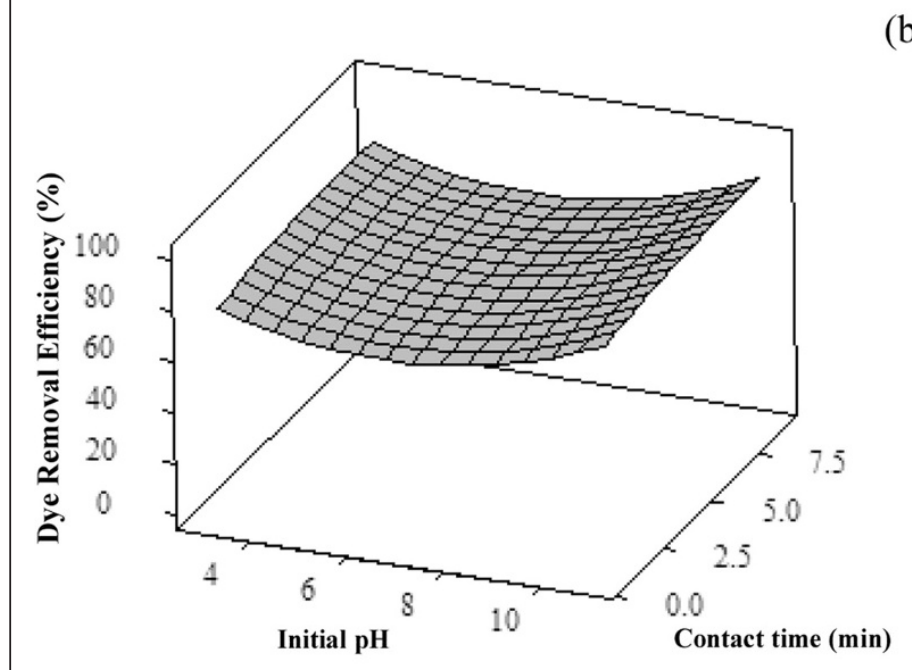

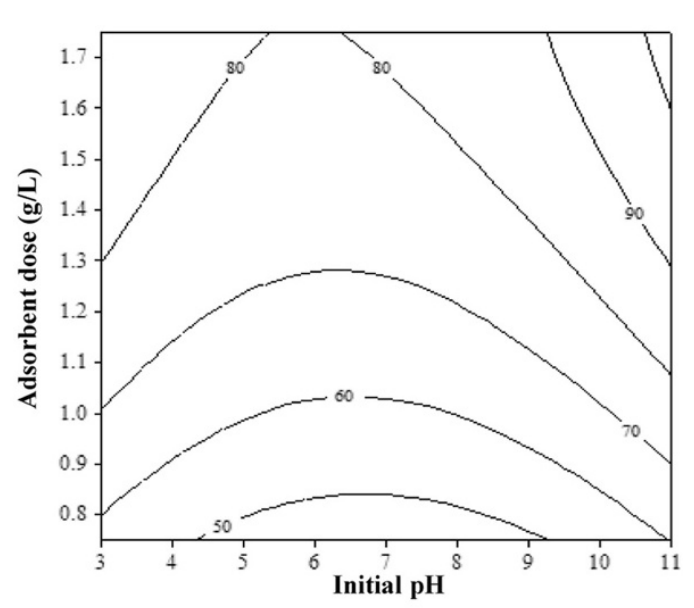

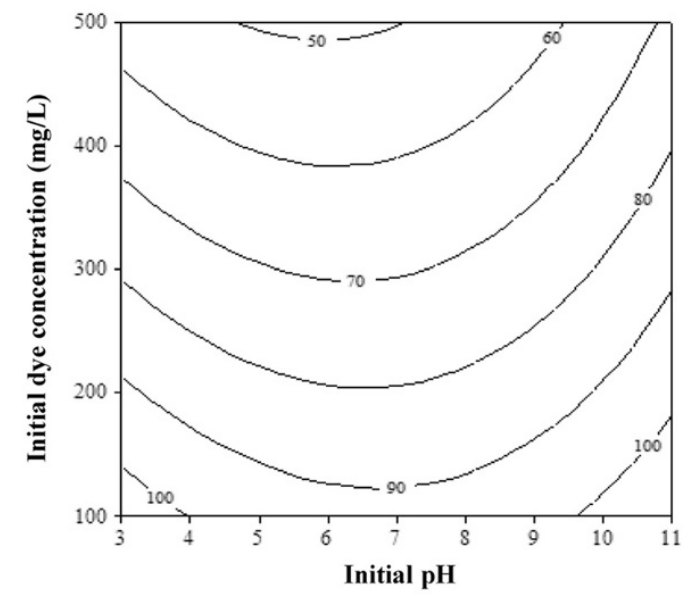

(b)

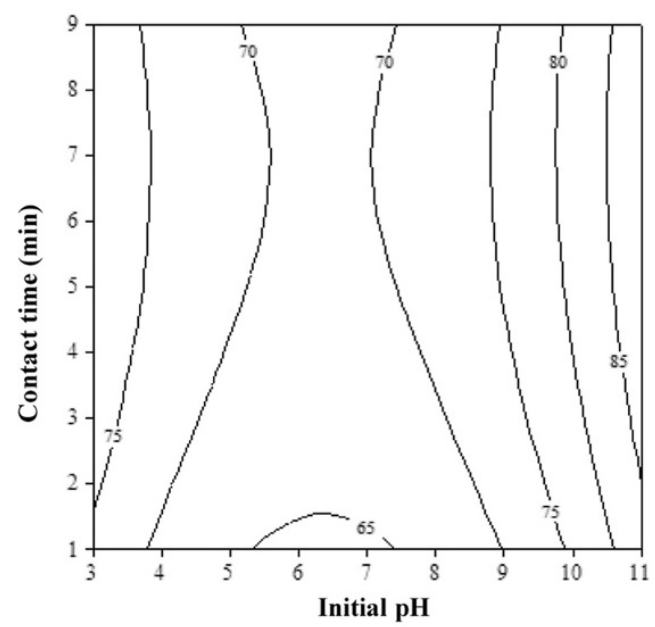

(c)

Figure 6 Surface corresponding contour plot as a function of initial $\mathrm{pH}$ and: (a) adsorbent dose (initial dye concentration of $300 \mathrm{mg} / \mathrm{l}$ and contact time of $5 \mathrm{~min}$ ) (b) initial dye concentration (adsorbent dose of $1.25 \mathrm{~g} / \mathrm{L}$ and contact time of $5 \mathrm{~min}$ ) (c) contact time (initial dye concentration of $300 \mathrm{mg} / \mathrm{l}$ and adsorbent dose of $1.25 \mathrm{~g} / \mathrm{L}$ ). 
residual. The effect of four operating variables of adsorption process including initial $\mathrm{pH}$, adsorbent dose, initial dye concentration, and contact time were examined. The BET method showed that the average $\mathrm{S}_{\mathrm{BET}}$ of $\mathrm{AC}$ was $825.46 \mathrm{~m}^{2} \mathrm{~g}^{-1}$. The results of this investigation presented that RSM is a powerful statistical optimization and modeling tool for RB19 removal using adsorption process.

\section{Competing interests}

The authors declare that they have no competing interests.

\section{Authors' contributions}

This work is part of the Master thesis of ER where MRA, Supervisor of the thesis, suggested the problem and read the paper and MR, Co-Supervisor of the thesis, helped in analysis of experiments. All authors read and approved the final manuscript.

\section{Acknowledgements}

The authors are grateful to the Amirkabir University of Technology (AUT) research fund for the financial support. In addition, the authors wish to express thanks to Ms. Armineh Azizi and Ms. Shabnam Sadri Moghaddam (PhD students of environmental engineering), and Ms. Lida Ezzedinloo for their assistance during experiments.

\section{Author details}

'Department of Civil and Environmental Engineering, Amirkabir University of Technology (AUT), Tehran, Iran. ${ }^{2}$ Department of Textile Engineering, Amirkabir University of Technology (AUT), Tehran, Iran.

Received: 27 December 2012 Accepted: 5 March 2014

Published: 28 March 2014

\section{References}

1. Santos SCR, Boaventura RAR: Adsorption modeling of textile dyes by sepiolite. Appl Clay Sci 2008, 42:137-145.

2. Crini G: Non-conventional low-cost adsorbents for dye removal: a review. Bioresour Technol 2006, 97:1061-1085.

3. Sadri MS, Alavi Moghaddam MR, Arami M: Decolorization of an acidic dye from synthetic wastewater by sludge of water treatment plant. Iran $J$ Environ Health Sci Eng 2010, 7:437-442.

4. Ehrampoush MH, Ghanizadeh G, Ghaneian MT: Equilibrium and kinetics study of reactive red 123 dye removal from aqueous solution by adsorption on eggshell. Iran J Environ Health Sci Eng 2011, 8:101-108.

5. Xu Y, Lebrun RE: Treatment of textile dye plant effluent by nanofiltration membrane. Separa Sci Technol 1999, 34:2501-2519.

6. Bechtold T, Burtscher E, Turcanu A: Cathodic decolorisation of textile wastewater containing reactive dyes using multi-cathode electrolyser. J Chem Technol Biotechnol 2001, 76:303-311.

7. Sadri MS, Alavi Moghaddam MR, Arami M: Coagulation/flocculation process for dye removal using sludge from water treatment plant: optimization through response surface methodology. J Hazard Mater 2010, 175:651-657.

8. Hosseini KE, Alavi Moghaddam MR, Hashemi SH: Investigation of decolorization kinetics and biodegradation of azo dye Acid Red 18 using sequential process of anaerobic sequencing batch reactor/moving bed sequencing batch biofilm reactor. Int Biodeter Biodeg 2012, 71:43-49.

9. Chatterjee S, Lee DS, Lee MW, Woo SH: Enhanced adsorption of congo red from aqueous solutions by chitosan hydrogel beads impregnated with cetyl trimethyl ammonium bromide. Bioresour Technol 2009, 100:2803-2809.

10. Samarghandi MR, Zarrabi M, Noori Sepehr M, Amrane A, Hossein Safari G, Bashiri S: Application of acidic treated pumice as an adsorbent for the removal of azo dye from aqueous solutions: kinetic, equilibrium and thermodynamic studies. Iran J Environ Health Sci Eng 2012, 9:101-108.

11. Lua AC, Yang T: Characteristics of activated carbon prepared from pistachio-nut shell by zinc chloride activation under nitrogen and vacuum conditions. J Colloid Inter Sci 2005, 290:505-513.

12. Benadjemia M, Millière L, Reinert L, Benderdouche N, Duclaux L: Preparation, characterization and Methylene Blue adsorption of phosphoric acid activated carbons from globe artichoke leaves. Fuel Process Technol 2011, 92:1203-1212.
13. Wu FC, Wu PH, Tseng RL, Juang RS: Preparation of activated carbons from unburnt coal in bottom ash with $\mathrm{KOH}$ activation for liquid-phase adsorption. J Environ Manage 2010, 91:1097-1102.

14. Ravikumar K, Ramalingam S, Krishnan S, Balu K: Application of response surface methodology to optimize the process variables for reactive red and acid brown dye removal using a novel adsorbent. Dyes Pigment 2006, 70:18-26.

15. Auta $\mathrm{M}$, Hameed BH: Optimized waste tea activated carbon for adsorption of methylene blue and acid blue 29 dyes using response surface methodology. Chem Eng J 2011, 175:233-243.

16. Liu Y, Wang J, Zheng Y, Wang A: Adsorption of methylene blue by kapok fiber treated by sodium chlorite optimized with response surface methodology. Chem Eng J 2012, 184:248-255.

17. Chatterjee S, Kumar A, Basu S, Dutta S: Application of response surface methodology for methylene blue dye removal from aqueous solution using low cost adsorbent. Chem Eng J 2012, 181:289-299.

18. Azizi A, Alavi Moghaddam MR, Arami M: Application of wood waste for a reactive dye removal from aqueous solutions: optimization through response surface methodology. J Environ Eng Manag. in press.

19. Liu Y, Zheng Y, Wang A: Response surface methodology for optimizing adsorption process parameters for methylene blue removal by a hydrogel composite. Adsorp Sci Technol 2010, 28:913-922.

20. Azizi A, Alavi Moghaddam MR, Arami M: Wood Waste from mazandaran wood and the paper industry as a low cost adsorbent for removal of a reactive dye. J Resid Sci Technol 2011, 8:21-28.

21. Khaled A, Nemr AE, Sikaily AE, Abdelwahab O: Removal of direct N blue106 from artificial textile dye effluent using activated carbon from orange peel: adsorption isotherm and kinetic studies. J Hazard Mater 2009, 165:100-110.

22. Mahmoodi NM, Hayati B, Arami M, Lan C: Adsorption of textile dyes on pine cone from colored wastewater: kinetic, equilibrium and thermodynamic studies. Desalination 2011, 268:117-125.

23. Sadri MS, Alavi Moghaddam MR, Aram M: A comparative study of acid red 119 dye adsorption onto dried sewage sludge and sewage sludge ash: isotherm, kinetic and desorption study. J Resid Sci Technol 2010, 7:199-207.

doi:10.1186/2052-336X-12-65

Cite this article as: Radaei et al:: Removal of reactive blue 19 from aqueous solution by pomegranate residual-based activated carbon: optimization by response surface methodology. Journal of Environmental Health Science \& Engineering 2014 12:65

\section{Submit your next manuscript to BioMed Central and take full advantage of:}

- Convenient online submission

- Thorough peer review

- No space constraints or color figure charges

- Immediate publication on acceptance

- Inclusion in PubMed, CAS, Scopus and Google Scholar

- Research which is freely available for redistribution 